\title{
Dual-Mediation Paths Linking Corporate Social Responsibility to Employee's Job Performance: A Multilevel Approach
}

\author{
Miaoying Fang ${ }^{1}$, Peng Fan ${ }^{2 *}$, Surya Nepal ${ }^{3}$ and Po-Chien Chang ${ }^{4}$ \\ ${ }^{1}$ Department of Human Resource Management, School of Economics and Management, Dongguan University \\ of Technology, Dongguan, China, ${ }^{2}$ Department of International Business and Management, School of Economics \\ and Management, Dongguan University of Technology, Dongguan, China, ${ }^{3}$ Department of Business Administration, \\ Changwon National University, Changwon, South Korea, ${ }^{4}$ Department of Management and Administration, Macau \\ University of Science and Technology, Taipa, Macau
}

\section{OPEN ACCESS}

Edited by: Giulio Arcangeli,

University of Florence, Italy

Reviewed by:

Dolores Gallardo Vázquez,

University of Extremadura, Spain

Ilaria Setti,

University of Pavia, Italy

*Correspondence:

Peng Fan

fanpeng@dgut.edu.cn

Specialty section

This article was submitted to

Organizational Psychology, a section of the journal

Frontiers in Psychology

Received: 30 September 2020 Accepted: 07 December 2020

Published: 14 January 2021

Citation:

Fang M, Fan P, Nepal S and Chang P-C (2021) Dual-Mediation

Paths Linking Corporate Social Responsibility to Employee's Job

Performance: A Multilevel Approach.

Front. Psychol. 11:612565.

doi: 10.3389/fpsyg.2020.612565
This study attempts to examine the direct impact of corporate social responsibility (CSR) initiatives on employees' job performance and the indirect relationships between CSR initiatives on employees' job performance via industrial relations climate and psychological contract fulfillment. Data were collected from 764 supervisor-subordinate dyads and 271 middle managers from 85 companies. Using a multilevel approach, the results showed that organizational-level CSR was positively related to employees' job performance. Moreover, the industrial relations climate and psychological contract fulfillment played mediating effects between CSR initiatives and job performance. This study provides novel theoretical evidence for why and how CSR initiatives improve job performance. Theoretical and practical implications for implementing CSR initiatives are discussed.

Keywords: corporate social responsibility, industrial relations climate, job performance, multilevel approach, psychological contract fulfillment

\section{INTRODUCTION}

Corporate social responsibility (CSR) refers to "context-specific organizational actions and policies that take into account stakeholders' expectations and the triple bottom line of economic, social, and environmental performance" (Aguinis, 2011, p. 855). After the global financial crisis in 2008, CSR has received a great deal of attention in the management field of research (Wang et al., 2017; Xiao et al., 2019). As a beneficial source of an organization's competitiveness and longterm sustainability, scholars have discussed the significant role of CSR at different levels. In the initial stage of CSR studies, researchers mainly focused on the macro perspective, exploring the role of CSR in organizational outcomes, such as financial performance (Godfrey et al., 2009) and organizational performance (Lindgreen et al., 2009). Alternatively, some scholars have concentrated on the association between CSR and individual outcomes at the microlevel (e.g., Lee et al., 2013; De Roeck et al., 2014; Glavas and Kelley, 2014). As a result, research fragmentations have been exacerbated by applying different theoretical frameworks (Aguinis and Glavas, 2012; Glavas, 2016). The understanding of the mechanisms linking CSR with employee outcomes seems to have been overlooked (Wang et al., 2017). In particular, the empirical testing of multiple mediation 
mechanisms based on individual perspective analysis remains limited (Glavas, 2016). Therefore, a multilevel approach to the mediation mechanism is key to understanding the underlying mechanisms of the relationship between CSR initiatives and employee outcomes.

To bridge the significant gaps of prior studies, this study attempts to provide dual-mediation paths linking CSR initiatives to employees' job performance with the adoption of a multilevel approach. Based on the social identity theory (SIT) (Tajfel and Turner, 1986) and social information processing theory (SIPT) (Salancik and Pfeffer, 1978), our study explores the direct effects of CSR initiatives on job performance and the indirect effects of CSR initiatives on job performance mediated via the industrial relations climate (IRC) construct. Although many of the microCSR studies have explored numerous mediating factors (e.g., organizational identification), scholars have suggested that future research should provide meaningful insights into variables related to stakeholder relations (Aguinis and Glavas, 2012). As an important element of organizational culture, the IRC refers to the quality of labor-management relations, and thus, it is likely to influence and be influenced by employee-management interactions in the workplace (Pyman et al., 2010). With rapid changes in the economic environment during the last two decades, industrial relations are considered as key factors capable of addressing CSR issues, with many Chinese enterprises making their best efforts to develop workplace relations aimed at generating outstanding performance (Chan and Nadvi, 2014). Therefore, this study endeavors to examine the significant impact that CSR initiatives mediated via IRC has on employee behavioral outcomes.

Regarding the social exchange theory (SET) (Blau, 1964), we seek to identify whether CSR initiatives may affect job performance through psychological contract fulfillment (PCF). As proposed by initial scholars, a psychological contract is considered to be an important means to understand the relationship between organizations and employees (Rousseau, 2001; Kutaula et al., 2020). It involves emotions, perceptions, and expectations as well as the urges for sensemaking in the workplace (Persson and Wasieleski, 2015). Thus, organizations could, at the best level, address most of the employees' expectations, thereby contributing to certain aspects that an organization takes care of Dixon-Fowler et al. (2019). Although CSR initiatives are driven by various stakeholders that have a powerful effect on employees' expectations, most studies have focused mostly on external stakeholders, and the relationships between CSR initiatives and internal stakeholders (i.e., employees) have rarely been investigated (Aguinis and Glavas, 2012; Dixon-Fowler et al., 2013). Therefore, we incorporate PCF into the hypothesized model and explore the mediating mechanism between CSR initiatives and employee job performance (Figure 1).

This study makes several contributions to the literature. First, our study extends CSR research by identifying the mediating mechanism underlying the CSR-employee outcomes relationship. Although CSR scholars have investigated various mediators between CSR initiatives and individuals' outcomes (e.g., Farooq et al., 2014; Glavas and Kelley, 2014), multiple mediating mechanisms have not received much consideration
(Glavas, 2016). This study fills previous gaps by providing a better understanding of CSR impacting on the employees' behavioral outcomes (i.e., job performance) through the mediating effect of IRC and PCF. Second, this study explores the approach of measuring CSR on multiple levels (Aguinis and Glavas, 2012). Numerous scholars have accessed an organization's CSR on an individual level and investigated the relationship between perceived CSR and different outcomes, such as job satisfaction (De Roeck et al., 2014), normative organizational commitment (Mory et al., 2016), and socially responsible behaviors (De Roeck and Farooq, 2018). However, multilevel research including both organizational and individual-level data is lacking (Jones et al., 2017). Thus, this study enriches the knowledge of microfoundations applicable to the CSR literature by utilizing a multilevel approach. Third, researches so far have put emphasis on Western contexts and lack enough empirical research related to Asia (Kutaula et al., 2020). The current study also makes an empirical contribution to the CSR literature by examining the role of CSR initiatives in employees' job performance in the Chinese organizational context.

\section{THEORETICAL BACKGROUND AND HYPOTHESES}

\section{CSR Initiatives and Job Performance}

Based on SIT, individuals consider themselves as salient to social categories, and individuals' self-conception is influenced by relevant social groups or organizations. Consequently, the social identity (ingroup or outgroup) may have a critical influence on people's attitudes and behaviors (Tajfel and Turner, 1986; Ali et al., 2020). Researchers offer empirical evidence of the vital role of CSR initiatives in affecting individuals' outcomes. Edwards and Kudret (2017) extended the CSR literature by exploring the influence of multifocal CSR perceptions on in-role job performance via affective commitment and organizational pride. Newman et al. (2019) investigated the impact of perceived CSR practices on employees' job performance and organizational citizenship behavior (OCB), which includes their positive contributions to their work environment that are not formally part of their job descriptions. Furthermore, a recent study demonstrated that external CSR initiatives could improve employees' job performance, while both external and internal CSR initiatives play indirect roles in improving job performance via job satisfaction (Story and Castanheira, 2019).

According to SIT, employees evaluate themselves via their organization's social status or standing and are likely to identify with an organization that holds high prestige. Since employees tend to have prosocial values and expect those values to be implemented by their organization, CSR initiatives may raise employees' attachment and identification to the organization (Wang et al., 2019). As a result, such a feeling of organizational identification may motivate employees to perform more positively, which in turn improves their job performance. Aligned with SIT, we propose that CSR initiatives will be positively related to employees' job performance. 


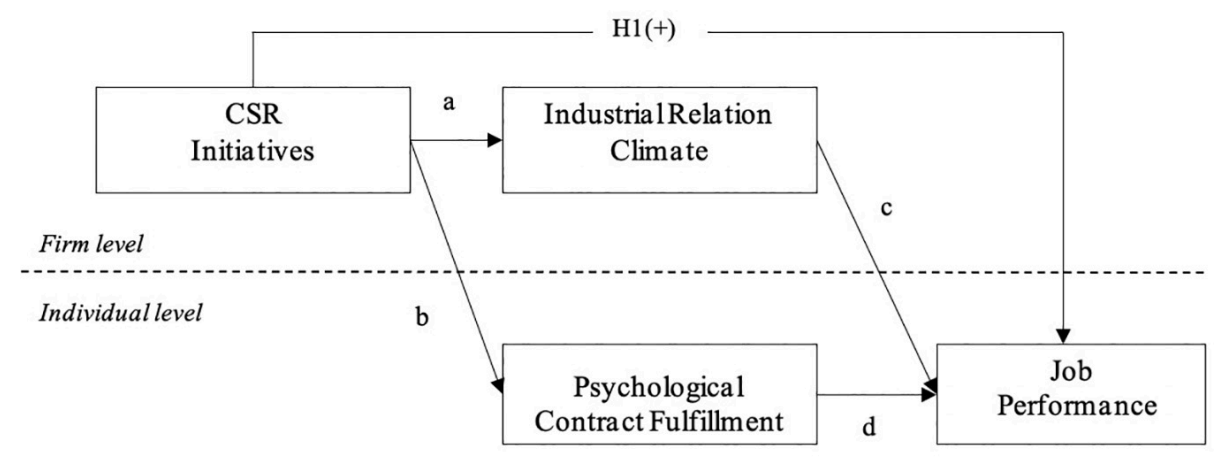

$\mathrm{H} 2(+)=$ CSR Initiatives $\rightarrow$ Industrial Relation Climate $\rightarrow$ Job Performance $(\mathrm{a} \times \mathrm{c})$

H3 $(+)=$ CSR Initiatives $\rightarrow$ Psychological Contract Fulfillment $\rightarrow$ Job Performance $(b \times d)$

FIGURE 1 | Conceptual model.

Hypothesis 1: CSR initiatives will have a positive association with employees' job performance.

\section{The Mediating Effect of Industrial Relations Climate}

Given the theoretical framework and empirical evidence presented by prior research, we propose that IRC mediates the link between CSR initiatives and job performance. According to SIPT, the environment where employees spend their time affects their attitudes toward an organization by directly providing attitudes, behavioral guidance, transferable beliefs, and needs (Salancik and Pfeffer, 1978). Employees are aware of their work environment, and the consequences of certain behaviors largely determine their actions. The theoretical background has been advanced by human resource management and organizational behavior literature, which suggests that an organization's CSR practices are significant resources that improve organizational culture and subsequent employees' attitudes and behaviors (Mossholder et al., 2011). As one of the most important organizational strategies, CSR initiatives care about both external and internal stakeholders as well as a culture that respects sustainability, in addition to profit maximization. CSR initiatives integrate the value of sustainability into organizational systems and motivate employees to react similarly in daily life (Schneider et al., 2013; Shen and Zhang, 2019). As such, the organization most probably develops an organizational IRC, which is the shared perception about the work environment targeted at addressing the mutual relations between the organization and various stakeholders.

In addition, numerous studies have proposed empirical evidence for the mediating role of organizational climates in organizational policies. Shedding light on the inputtransformation-output mechanism, Masters et al. (2006) presented insights on an organization's management practices, which can affect employees' attitudes, behaviors, and organizational outcomes. Xi et al. (2017) also suggested that partnership practices could positively affect organizational IRC and, in turn, improve employees' attitudes. Based on these findings, IRC establishes a link between CSR initiatives and employees' job performance, indicating that IRC plays a mediating role in the association between CSR initiatives and job performance. Thus, we postulate:

Hypothesis 2: IRC mediates the relationship between CSR initiatives and job performance.

\section{The Mediating Role of Psychological Contract Fulfillment}

Compared with explicit terms and requirements in a written form, the psychological contract provides ideas with respect to employee perceptions and beliefs about their implicit obligations (Rousseau, 2001). It highlights the cognitive perception of mutual obligations established between employees and organizations (Robinson and Rousseau, 1994). The psychological contract theory is deeply grounded in SET (Blau, 1964) and reciprocity (Gouldner, 1960). Employees' affinity to reciprocate the organization's values depends on whether the organization fulfills their needs and expectations (Farnese et al., 2018). However, when employees perceive a mismatched relationship between their work effort and acceptable resources as well as inducements, the exchange is likely to be considered an unbalanced state. Consequently, employees may get an impression that the psychological contract is not being honored (Birtch et al., 2016).

Based on SET, a wide variety of researchers have examined the antecedents and outcomes of PCF. For example, some predictors could create a favorable environment that can meet employees' expectations, which boosts the relationship between employees and the organization. Organizational factors, including HR practices (Latorre et al., 2016, 2020), leadership (Jiang et al., 2017), and organizational culture (Richard et al., 2009), have been recognized as key antecedents of the psychological contract. In addition, employees' attitudes and behavior outcomes have been investigated, including organizational commitment (Jabeen et al., 2015), job satisfaction (Raja et al., 2011), turnover intention (Chen and $\mathrm{Wu}, 2017$ ), organizational citizenship behavior 
(Shih and Chen, 2011), and job performance (Cheung et al., 2017). In the current study, we seek to explore the mediating effect of PCF on the relationship between CSR initiatives and job performance. According to previous evidence, successful exchanges would be shaped as a consequence of organizations adopting organizational-level CSR initiatives (e.g., providing employees' needs and promoting the well-being of society), as well as care and concern for its stakeholders (Kutaula et al., 2020). When the fulfillment of organizational responsibilities and obligations raises employees' expectations, employees would demonstrate loyalty and commitment to the organization and, subsequently, improve their job performance. Thus, we argue that:

Hypothesis 3: Psychological contract fulfillment mediates the relationship between CSR initiatives and job performance.

\section{RESEARCH METHODS}

\section{Sample and Procedure}

Given the nature of our study, the samples in this study were collected based on companies that had CSR strategies listed in the local government system. To recruit the participants, we first contacted these companies by telephone and explained the process of our study. After showing the purpose of the current study, 85 companies (89.47\%) from different sectors agreed to participate in our research. Before providing the questionnaires, we sent cover letters, including detailed instructions to each company's human resources (HR) department. The HR director was asked to select employees randomly to avoid response bias. To minimize common method bias (Podsakoff et al., 2012), our data were collected from multiple sources, including middle managers, HR directors, frontline employees, and their direct superiors. The first part of the questionnaire was for HR directors to provide basic information about the company, including its industry, size, and ownership. Although top managers have been regarded as designers of CSR strategy within organizations, middle managers play a critical role in enforcing top-down vision and implementing CSR strategies in practice (Maon et al., 2009). Thus, middle managers were asked to access the CSR initiatives of their companies. The data on IRC and PCF were collected from employees, and their direct supervisors were responsible for evaluating employees' job performance. After removing invalid questionnaires, we were left with valid responses from 764 supervisor-subordinate dyads and 271 middle managers who had assessed the questionnaires. The response rates were thus $93.63 \%$ for the employees and $92.90 \%$ for the companies.

Participating companies ranged in size of employees from 100 to 13,000 ; 6 of the 79 firms were in the agricultural industry, 18 were in the manufacturing industry, and 55 were in the service industry. Among those companies, $44.4 \%$ were stateowned enterprises, $33.2 \%$ were private-owned enterprises, and $17.3 \%$ were foreign-owned enterprises.

Of the 764 employees sampled, gender-wise, $51.2 \%$ were male; education-wise, $7.6 \%$ were high school and below, $20.8 \%$ were junior college, $67.0 \%$ graduated from university, and $4.6 \%$ had a master's degree; age-wise, $12.2 \%$ were $18-25$ years old, $53.8 \%$ were aged $26-35$ years, $31.1 \%$ were aged $36-45$, and $2.9 \%$ were aged 46-55 years; and tenure-wise, $88.2 \%$ had worked for more than 1 year (Table 1 ).

\section{Measures}

We used a five-point Likert scale ranging from 1 (strongly disagree) to 5 (strongly agree) to measure all variables in this study. Since the scales were originally developed in English, a back-translated method was adopted to ensure the accuracy of the meaning (Brislin, 1980). We invited two English-Chinese bilinguals to undertake the translation of measurements in our study. Bilingual 1 translated English measurements into Chinese and then bilingual 2 translated the newly translated version back into English. After the English-Chinese and Chinese-English translation processes, one researcher compared the original items with the newly translated version. The final pretesting step was undertaken with three HR experts to ensure the relevance and validity of the measurements. After confirming the original language and back-translated versions without any perceived differences, the questionnaires were distributed to the employees and their supervisors.

\section{CSR Initiatives}

We used the 17-items scale adopted from Turker (2009) to measure CSR initiatives. Sample items for each subdimension are as follows: "Our company makes investment to create a better life for future generations," "The management of our company is primarily concerned with employees' needs and wants," "Our company provides full and accurate information about its products to its customers," and "Our company complies with legal regulations completely and promptly.” The Cronbach's alpha of each subdimension was 0.90, 0.86, 0.87, and 0.83, respectively. Following the suggestions by Hur et al. (2018), we employed an overall construct to measure organizational CSR. The confirmatory factor analyses showed an acceptable fit for the one-factor structure: $\chi^{2} / d f=1.18$, GFI $=0.95$,

\begin{tabular}{|c|c|c|c|}
\hline & & Frequency & Percent (\%) \\
\hline \multirow[t]{2}{*}{ Gender } & Male & 391 & 51.2 \\
\hline & Female & 373 & 48.8 \\
\hline \multirow[t]{4}{*}{ Age } & $18-25$ & 93 & 12.6 \\
\hline & $26-35$ & 411 & 53.8 \\
\hline & $36-45$ & 238 & 31.1 \\
\hline & $46-55$ & 22 & 2.9 \\
\hline \multirow[t]{4}{*}{ Education } & High school and below & 58 & 7.6 \\
\hline & Junior college & 159 & 20.8 \\
\hline & Undergraduate & 512 & 67.0 \\
\hline & Master's degree & 35 & 4.6 \\
\hline \multirow[t]{4}{*}{ Tenure } & Less than 1 year & 90 & 11.8 \\
\hline & $1-5$ years & 214 & 28.0 \\
\hline & $6-10$ years & 226 & 29.6 \\
\hline & more than 10 years & 234 & 30.6 \\
\hline
\end{tabular}

$N=764$ 
comparative fit index $(\mathrm{CFI})^{\circ}=0.99$, root mean square error of approximation $(\mathrm{RMSEA})=0.03$, and standardized root mean square residual $(\mathrm{SRMR})=0.04$. The Cronbach's alpha for the overall CSR scale was 0.90 .

\section{Industrial Relations Climate}

IRC was measured using a six-item scale developed by Hammer et al. (1991). The scale was subsequently validated by Snape and Redman (2012). A sample item is "Workers and management distrust one another (R)." The Cronbach's alpha for the overall IRC scale was 0.94 .

\section{Psychological Contract Fulfillment}

We measured PCF using a 14-item scale from Shih and Chen (2011). A sample item is "This company is responsive to employee concerns and well-being." Cronbach's alpha for PCF was 0.88 .

\section{Job Performance}

We measured job performance using a 19-item scale from Van Scotter and Motowidlo (1996). A sample item for this scale is "He/She takes the initiative to solve a work problem." The Cronbach's alpha for job performance was 0.94 .

\section{Control Variables}

Prior research has indicated that employees' demographic variables are associated with job performance (Newman et al., 2015). Thus, we control for employee gender, education, and age, as well as organizational tenure, and tested whether job performance could be influenced by these demographic variables.

\section{Analytical Strategy}

Given the nested structure of the data, we calculated intraclass correlation coefficients (ICCs) and interrater agreement values (Rwg) to assess the validity of aggregating data for CSR initiatives and industrial relations climate. Reliability of score within group ICC(1) estimates the proportion of the total variance of a measure that is explained by unit membership, while the reliability of mean group score ICC(2) measures the reliability of the group mean scores (Bliese, 2000). Rwg represents the within-group agreement for the given measure. The results of intraclass correlation coefficients $[\operatorname{ICC}(1)=0.35, \operatorname{ICC}(2)=0.86]$ as well as the interrater agreement value [Rwg $=0.77]$ supported the aggregation of the employees' individual responses to the organizational-level IRC (Bliese, 2000). Moreover, we tested the aggregation statistics for CSR initiatives that were answered by the middle manager $(n=271)$, supporting an aggregation to the firm level $[\operatorname{ICC}(1)=0.43, \operatorname{ICC}(2)=0.80$, Rwg $=0.96]$. The inbetween parts of the model were designed to test Hypotheses 1, 2, and 3 , including the direct and indirect effects of organizational CSR initiatives on employees' job performance through IRC and PCF. Since the collected data were nested within organizations, we employed multilevel structural equation modeling (MSEM) to examine the proposed hypotheses by using Mplus 7.4 software (Muthén and Muthén, 1998-2018). According to previous studies, MSEM can overcome the limitations of traditional multilevel mediation analysis. Moreover, we adopted the Monte Carlo method to assess the mediating effect via 95\% confidence interval results (Preacher et al., 2010).

\section{RESULTS}

\section{Confirmatory Factor Analyses}

To test the distinctiveness among three individual-level variables, including industrial relations climate, psychological PCF, and job performance, we conducted a series of confirmatory factor analyses. The three-factor model showed a good model fit, $\chi^{2}=1,025.72, d f=693$, CFI $=0.98$, Tucker-Lewis index $(\mathrm{TLI})=0.98, \mathrm{SRMR}=0.03, \mathrm{RMSEA}=0.03$. Compared with the alternative models, the three-factor model indicated a better model fit. Furthermore, we employed multilevel confirmatory factor analysis to estimate the model fit of the hypothesized model $\left(\chi^{2}=2,205.15, d f=1,958\right.$, CFI $=0.99$, TLI $=0.99$, SRMR $=0.03$, RMSEA $=0.01)$. The results suggested that the factor structure developed in our model was acceptable at between-group levels of analysis (Table 2).

\section{Descriptive Statistics}

Table 3 shows the descriptive statistics, including the means, standard deviations, and correlations for the individual- and organizational-level variables. Middle managers' perceptions of CSR initiatives were positively related to the IRC $(r=0.36$, $p<0.01)$, PCF $(r=0.27, p<0.01)$, and job performance $(r=0.55$, $p<0.01)$. Moreover, the IRC $(r=0.27, p<0.01)$ and PCF $(r=0.49, p<0.01)$ were all positively related to employees' job performance.

\section{Hypotheses Testing}

Following the suggestions by Boehm et al. (2014), we investigated our assumed hypotheses using MSEM. The overall results of the proposed model indicated a good fit $\left(\chi^{2}=1,409.78, d f=1,055\right.$, $\mathrm{CFI}=0.97$, TLI $=0.97, \mathrm{SRMR}=0.03, \mathrm{RMSEA}=0.02$ ). Hypothesis 1 proposed that CSR initiatives would have a positive effect on

TABLE 2 | Results of confirmatory factor analysis.

\begin{tabular}{|c|c|c|c|c|c|c|}
\hline & $x^{2}$ & $d f$ & CFI & TLI & SRMR & RMSEA \\
\hline Three factors & 1025.72 & 693 & 0.98 & 0.98 & 0.03 & 0.03 \\
\hline Two factors $(\mathrm{IRC}+\mathrm{JP})+\mathrm{PCF}$ & 4277.95 & 699 & 0.80 & 0.79 & 0.08 & 0.08 \\
\hline Two factors (IRC + PCF $)+J P$ & 5102.24 & 699 & 0.75 & 0.74 & 0.10 & 0.09 \\
\hline One factor $(\mathrm{IRC}+\mathrm{PCF}+\mathrm{JP})$ & 8666.81 & 702 & 0.55 & 0.53 & 0.13 & 0.12 \\
\hline
\end{tabular}

IRC, industrial relations climate; PCF, psychological contract fulfilment; JP, job performance. 
TABLE 3 | Means, standard deviation, and correlations among variables.

\begin{tabular}{|c|c|c|c|c|c|c|c|c|c|c|}
\hline & Mean & SD & 1 & 2 & 3 & 4 & 5 & 6 & 7 & 8 \\
\hline \multicolumn{11}{|l|}{ Individual level } \\
\hline 1. Gender & 0.51 & 0.50 & & & & & & & & \\
\hline 2. Age & 2.25 & 0.70 & 0.02 & & & & & & & \\
\hline 3. Education & 2.69 & 0.68 & 0.00 & $0.12^{\star \star}$ & & & & & & \\
\hline 4. Tenure & 2.79 & 1.01 & -0.04 & $0.32^{\star \star}$ & $0.19^{\star \star}$ & & & & & \\
\hline 5. PCF & 2.97 & 0.64 & 0.05 & 0.02 & -0.01 & -0.01 & $(0.88)$ & & & \\
\hline 6. JP & 3.19 & 0.86 & 0.02 & 0.03 & 0.03 & 0.02 & $0.49^{\star \star}$ & $(0.94)$ & & \\
\hline \multicolumn{11}{|l|}{ Firm level } \\
\hline 7. CSR initiatives & 2.82 & 0.57 & -0.03 & 0.04 & -0.02 & 0.03 & $0.27^{\star \star}$ & $0.55^{\star \star}$ & $(0.90)$ & \\
\hline 8. IRC & 3.17 & 0.89 & 0.05 & 0.02 & 0.02 & 0.02 & 0.07 & $0.27^{\star \star}$ & $0.36^{\star \star}$ & $(0.94)$ \\
\hline
\end{tabular}

${ }^{* *} p<0.01$. Reliability coefficients were listed on the diagonal.

job performance. As shown in Table 4, CSR initiatives were significantly related to employees' job performance $(\beta=0.57$, $p<0.001)$. Hence, Hypothesis 1 was supported.

Hypothesis 2 postulated that industrial relations climate mediates the relationship between CSR initiatives and job performance. The results revealed that industrial relations climate played a mediating role in the relationship between CSR initiatives and job performance, with an indirect effect of 0.12 (95\% CI $=[0.048,0.205], p<0.01)$. Thus, Hypothesis 2 was supported.

Hypothesis 3 predicted that PCF mediates the relationship between CSR initiatives and job performance. The results showed that PCF played a mediating role in the relationship between CSR initiatives and job performance, with an indirect effect of 0.07 (95\% CI $=[0.019,0.140], p<0.05)$. Thus, Hypothesis 3 was also supported.

\section{DISCUSSION}

During the last two decades, scholars have called for investigating the microfoundation of CSR research and exploring employees' responses to CSR (Rupp et al., 2013; Wang et al., 2017). Our study was conducted to examine the direct effect of CSR initiatives on employees' job performance. In addition, we explored the mediating role of IRC and PCF in the relationship between CSR initiatives on job performance by considering SET and SIPT (Blau, 1964; Salancik and Pfeffer, 1978). Our results support the hypothesized relationships. The results show that, in addition to the direct impact of CSR initiatives on job performance, CSR initiatives also have an indirect effect via IRC and PCF. This study presents several theoretical and practical implications.

\section{Theoretical Implications}

This research enriches the CSR literature in four notable approaches. First, the results revealed that CSR initiatives were positively related to employees' job performance. Although several studies have examined the role of employees' perceptions of CSR in predicting job attitudes and job behaviors (Newman et al., 2019), this study indicates that CSR activities that benefit social and non-social stakeholders can also improve employees' positive outcomes. The current study verified prior studies by
TABLE 4 | Results of cross-level indirect effects.

\begin{tabular}{lcc}
\hline Indirect effect & Indirect effect & Confidence interval \\
\hline $\begin{array}{l}\text { Cross-level indirect effect } \\
\text { CSR } \rightarrow \text { industrial relations } \\
\text { climate } \rightarrow \text { job performance }\end{array}$ & $0.12^{* \star}$ & {$[0.048,0.205]$} \\
$\begin{array}{l}C S R \rightarrow \text { psychological } \\
\text { contract } \rightarrow \text { job performance }\end{array}$ & $0.07^{*}$ & {$[0.019,0.140]$} \\
${ }^{*} p<0.05,{ }^{* *} p<0.01$. & & \\
\end{tabular}

supporting the hypothesis that CSR initiatives would have a positive effect on employee work behavior (e.g., Wang et al., 2019). The results of this study suggest that when an organization implements CSR activities, employees may feel a sense of belonging and identification with the organization. Since CSR is a critical source of employees' pride, they may feel that they should achieve higher performance in organizations with a good societal reputation. Therefore, this study contributes to SIT by identifying the CSR-job performance relationship.

Second, the results support the idea put forth by Glavas (2016), who proposed that an integrated image of CSR should be built by incorporating analysis at the individual level. Prior CSR research is mostly conducted at the macro and institutional levels, which focus on the impact on organizational performance (Frynas and Yamahaki, 2016; Serra-Cantallops et al., 2018). However, our findings suggest that CSR initiatives are interpreted as the organization's social responsibility activities that could improve employees' behavioral outcomes. Thus, our study enriches the CSR literature by interpreting CSR as an organizational-level predictor of job performance.

Third, this study contributes to existing research by examining dual mediating mechanisms in the relationship between CSR initiatives and job performance. By confirming the mediating effect of IRC and PCF in CSR-job performance relationships, the current study responds to the call to explore stakeholder relations mediators (Aguinis and Glavas, 2012). The findings of this study show that CSR initiatives are considered significant signals of organizations' sustainable practices and are likely to promote harmonious organization-employee relationships. These are identified as centrally important issues in building a long-term employment relationship that is likely to reciprocally improve 
between organizations and employees (Guest, 2004; Latorre et al., 2016). Consequently, both IRC and PCF are conducive to improving employees' productivity. To the best of our knowledge, this is the first study to explore the relationship between CSR and job performance, accounting for dual mediators of IRC and PCF. Moreover, our study bridged multilevel gaps, thereby unveiling the black box of the transmitting processes right from CSR initiatives to job performance. Therefore, these findings shed light on establishing an integrated framework about why and how organizational CSR initiatives affect employees' behavior.

Finally, although IRC is a crucial organizational factor that could predict employees' outcomes (e.g., Pyman et al., 2010; Valizade et al., 2016; Fortin-Bergeron et al., 2018), in the existing IRC literature, there are few studies with a non-Western context. Mirroring China's rapid growth, the Chinese government has implemented several reforms to build harmonious labor relations (Newman et al., 2019). However, labor relations problems in Chinese enterprises have steadily increased (Xi et al., 2017), which affects the performance and development of enterprises. It is worth further exploring whether the research results of IRC based on the Western cultural context are applicable to Chinese contexts. Thus, the current study also provides an avenue for researchers to compare a series of IRC practices from the cross-cultural perspective and helps to build more universally acceptable theories.

\section{Managerial Implications}

The findings of the current study also provide some practical implications. First, although there are inconsistent scholarly conclusions relating CSR's benefits to increasing additional costs, our study demonstrates that CSR initiatives as are a win-win strategy that could improve employee's job performance. Thus, middle managers should be aware that an organization's actual CSR initiatives may influence employees' behaviors, which in turn improve organizational competitiveness. In order to increase employees' job performance, organizations should allocate more resources to implementing CSR initiatives. In addition, we suggest that organizations should implement CSR initiatives encompassing social and non-social dimensions that reflect the company's management philosophy and, thus, implement CSR initiatives into daily operations and management activities.

Second, the results suggest that CSR initiatives may also affect the principal internal stakeholders (McWilliams and Siegel, 2001). To facilitate better job performance, organizations should communicate regularly to employees about CSR initiatives and the ways in which these sustainable practices affect society. We suggest that organizations should focus on promoting internal CSR initiatives. Employees are the major ones who benefit from internal CSR initiatives, and in turn, they will be obliged to respond positively to the organization (Bhattacharya et al., 2009; De Roeck et al., 2014). Thus, organizations should implement more CSR initiatives to employees, such as developing a fair reward system for employees, providing them learning and training opportunities.

Third, given the mediating role of the results, positive CSR influences job performance via IRC and PCF. Since the critical role of workplace partnership is creating positive industrial relations, organizations should consider how CSR initiatives are experienced by employees and their degree of participation in management activities. Additionally, as psychological contracts are framed in accordance with CSR communications for employees who are perceived as internal stakeholders (Maignan and Ferrell, 2004), organizations are recommended to reinforce communications with CSR promises to social and non-social stakeholders and to proactively seek feedback from employees thereon (Kiazad et al., 2019).

\section{Limitations and Future Research}

This study has a few limitations that should be considered in future research. First, this study uses multilevel sources to verify the relationship between various variables, which can effectively overcome the common method bias issue (Podsakoff et al., 2012). However, due to the limitation of cross-sectional data, causal inference on the relationship could not be established in this study. Thus, we suggest that future studies could employ a longitudinal design to offer meaningful evidence to support the findings of our study. Second, this study adopted a multilevel approach that introduced dual mediators, namely IRC and PCF, to examine the positive consequences of CSR initiatives. However, antecedents of CSR initiatives have been neglected in our hypothesized model. Scholars could consider the combination of multitheory (e.g., stakeholder theory and legitimacy theory) to illustrate how social and environmental resources affect CSR activities (Frynas and Yamahaki, 2016). Third, although the findings of this study indicate that CSR initiatives could improve job performance, prior studies have stressed the boundary condition that may influence employees' CSR judgments that subsequently affect the effectiveness of CSR initiatives. Therefore, other moderating variables, such as managers' directive leadership, should be introduced to our model and explain when and how CSR initiatives could successfully lead to employees' attitudes and behavioral outcomes.

\section{DATA AVAILABILITY STATEMENT}

The raw data supporting the conclusions of this article will be made available by the authors, without undue reservation.

\section{ETHICS STATEMENT}

Ethical approval was not provided for this study on human participants because ethical review and approval was not required for the study on human participants in accordance with the local legislation and institutional requirements. Written informed consent from the participants was not required to participate in this study in accordance with the national legislation and the institutional requirements. Written informed consent for participation was not required for this study in accordance with the national legislation and the institutional requirements. Written informed consent was not obtained from 
the individual(s) for the publication of any potentially identifiable images or data included in this article.

\section{AUTHOR CONTRIBUTIONS}

MYF designed the study, wrote the manuscript, and collected the data. PF wrote the manuscript and analyzed the data. SN and P-CC reviewed and revised the manuscript. All authors contributed to the article and approved the submitted version.

\section{REFERENCES}

Aguinis, H. (2011). "Organizational responsibility: doing good and doing well," in APA Handbook of Industrial and Organizational Psychology, Vol. 3, ed. S. Zedeck (Washington, DC: American Psychological Association), 855-879. doi: 10.1037/12171-024

Aguinis, H., and Glavas, A. (2012). What we know and don't know about corporate social responsibility: a review and research agenda. J. Manag. 38, 932-968. doi: $10.1177 / 0149206311436079$

Ali, H. Y., Asrar-ul-Haq, M., Amin, S., Noor, S., Haris-ul-Mahasbi, M., and Aslam, M. K. (2020). Corporate social responsibility and employee performance: the mediating role of employee engagement in the manufacturing sector of Pakistan. Corp. Soc. Responsib. Environ. Manag. 27, 2908-2919. doi: 10.1002/ csr.2011

Bhattacharya, C. B., Korschun, D., and Sen, S. (2009). Strengthening stakeholder-company relationships through mutually beneficial corporate social responsibility initiatives. J. Bus. Ethics 85, 257-272. doi: 10.1007/s10551-008-9730-3

Birtch, T. A., Chiang, F. F. T., and Van Esch, E. (2016). A social exchange theory framework for understanding the job characteristics-job outcomes relationship: the mediating role of psychological contract fulfillment. Int. J. Hum. Resour. Manag. 27, 1217-1236. doi: 10.1080/09585192.2015.1069752

Blau, P. M. (1964). Exchange and Power in Social Life. New York, NY: Wiley.

Bliese, P. D. (2000). "Within-group agreement, non-independence, and reliability: implications for data aggregation and analysis," in Multilevel Theory, Research, and Methods in Organizations: Foundations, Extensions, and New Directions, eds K. J. Klein and S. W. J. Kozlowski (San Francisco, CA: Jossey-Bass).

Boehm, S. A., Kunze, F., and Bruch, H. (2014). Spotlight on age-diversity climate: the impact of age-inclusive HR practices on firm-level outcomes. Pers. Psychol. 67, 667-704. doi: 10.1111/peps. 12047

Brislin, R. W. (1980). "Translation and content analysis of oral and written material," in Handbook of Cross-cultural Psychology, eds H. C. Triandis and J. W. Berry (Boston, MA: Allyn \& Bacon), 398-444.

Chan, C. K. C., and Nadvi, K. (2014). Changing labour regulations and labour standards in China: retrospect and challenges. Int. Labour Rev. 153, 513-534. doi: 10.1111/j.1564-913X.2014.00214.x

Chen, T. J., and Wu, C. M. (2017). Improving the turnover intention of tourist hotel employees: transformational leadership, leader-member exchange, and psychological contract breach. Int. J. Contemp. Hosp. Manag. 29, 1914-1936. doi: 10.1108/IJCHM-09-2015-0490

Cheung, M. F. Y., Wong, C. S., and Yuan, G. Y. (2017). Why mutual trust leads to highest performance: the mediating role of psychological contract fulfillment. Asia Pac. J. Hum. Resour. 55, 430-453. doi: 10.1111/1744-7941.12117

De Roeck, K., and Farooq, O. (2018). Corporate social responsibility and ethical leadership: investigating their interactive effect on employees' socially responsible behaviors. J. Bus. Ethics 151, 923-939. doi: 10.1007/s10551-0173656-6

De Roeck, K., Marique, G., Stinglhamber, F., and Swaen, V. (2014). Understanding employees' responses to corporate social responsibility: mediating roles of overall justice and organisational identification. Int. J. Hum. Resour. Manag. 25, 91-112. doi: 10.1080/09585192.2013.781528

Dixon-Fowler, H., O'Leary-Kelly, A., Johnson, J., and Waite, M. (2019). Sustainability and ideology-infused psychological contracts: an organizationaland employee-level perspective. Hum. Resour. Manag. Rev. 30:100690. doi: 10.1016/j.hrmr.2019.100690

\section{FUNDING}

This study was supported by the National Natural Science Foundation of China (No. 71603048), the Dongguan University of Technology "Research Team on Regional Innovation System and Technology Human Resource Management" (No. TDQN2019013), and Humanities and Social Science in Guangdong Province, China: Pearl River Delta Industrial Ecology Research Center (Grant No. 2016WZJD005).

Dixon-Fowler, H. R., Slater, D. J., Johnson, J. L., Ellstrand, A. E., and Romi, A. M. (2013). Beyond "does it pay to be green?" a meta-analysis of moderators of the CEP-CFP Relationship. J. Bus. Ethics 112, 353-366. doi: 10.1007/s10551-0121268-8

Edwards, M. R., and Kudret, S. (2017). Multi-foci CSR perceptions, procedural justice and in-role employee performance: the mediating role of commitment and pride. Hum. Resour. Manag. J. 27, 169-188. doi: 10.1111/1748-8583.12140

Farnese, M. L., Livi, S., Barbieri, B., and Schalk, R. (2018). "You can see how things will end by the way they begin": the contribution of early mutual obligations for the development of the psychological contract. Front. Psychol. 9:543. doi: 10.3389/fpsyg.2018.00543

Farooq, M., Farooq, O., and Jasimuddin, S. M. (2014). "Employees response to corporate social responsibility: exploring the role of employees" collectivist orientation'. Eur. Manag. J. 32, 916-927. doi: 10.1016/j.emj.2014.03.002

Fortin-Bergeron, C., Doucet, O., and Hennebert, M. A. (2018). The role of management and trade union leadership on dual commitment: the mediating effect of the workplace relations climate. Hum. Resour. Manag. 28, 462-478. doi: 10.1111/1748-8583.12191

Frynas, J. G., and Yamahaki, C. (2016). Corporate social responsibility: review and roadmap of theoretical perspectives. Bus. Ethics 25, 258-285. doi: 10.1111/beer. 12115

Glavas, A. (2016). Corporate social responsibility and organizational psychology: an integrative review. Front. Psychol. 7:144. doi: 10.3389/fpsyg.2016.00144

Glavas, A., and Kelley, K. (2014). The effects of perceived corporate social responsibility on employees. Bus. Ethics Q. 24, 165-202. doi: 10.5840/ beq20143206

Godfrey, P. C., Merrill, C. B., and Hansen, J. M. (2009). The relationship between corporate social responsibility and shareholder value: an empirical test of the risk management hypothesis. Strateg. Manag. J. 30, 425-445. doi: 10.3389/fpsyg. 2016.00796

Gouldner, H. P. (1960). Dimensions of organizational commitment. Adm. Sci. Q. 4, 468-490. doi: 10.2307/2390769

Guest, D. E. (2004). The psychology of the employment relationship: an analysis based on the psychological contract. Appl. Psychol. 53, 541-555. doi: 10.1111/j. 1464-0597.2004.00187.x

Hammer, T. H., Currall, S. C., and Stern, R. N. (1991). Worker representation on boards of directors: a study of competing roles. ILR Rev. 44, 661-668. doi: 10.1177/001979399104400404

Hur, W. M., Moon, T. W., and Ko, S. H. (2018). How employees' perceptions of CSR increase employee creativity: mediating mechanisms of compassion at work and intrinsic motivation. J. Bus. Ethics 153, 629-644. doi: 10.1007/s10551016-3321-5

Jabeen, F., Behery, M., and Elanain, H. A. (2015). Examining the relationship between the psychological contract and organisational commitment: the mediating effect of transactional leadership in the UAE context. Int. J. Organ. Anal. 23, 102-122. doi: 10.1108/IJOA-10-2014-0812

Jiang, H., Chen, Y., Sun, P., and Yang, J. (2017). The relationship between authoritarian leadership and employees' deviant workplace behaviors: the mediating effects of psychological contract violation and organizational cynicism. Front. Psychol. 8:732. doi: 10.3389/fpsyg.2017.0 0732

Jones, D. A., Willness, C. R., and Glavas, A. (2017). When corporate social responsibility (CSR) meets organizational psychology: new frontiers in microCSR research, and fulfilling a quid pro quo through multilevel insights. Front. Psychol. 8:520. doi: 10.3389/fpsyg.2017.00520 
Kiazad, K., Kraimer, M. L., and Seibert, S. E. (2019). More than grateful: how employee embeddedness explains the link between psychological contract fulfillment and employee extra-role behavior. Hum. Relations 72, 1315-1340. doi: 10.1177/0018726718806352

Kutaula, S., Gillani, A., and Budhwar, P. S. (2020). An analysis of employment relationships in Asia using psychological contract theory: a review and research agenda. Hum. Resour. Manag. Rev. 30:100707. doi: 10.1016/j.hrmr.2019.100707

Latorre, F., Guest, D., Ramos, J., and Gracia, F. J. (2016). High commitment HR practices, the employment relationship and job performance: a test of a mediation model. Eur. Manag. J. 34, 328-337. doi: 10.1016/j.emj.2016.05.005

Latorre, F., Ramos, J., Gracia, F. J., and Tomás, I. (2020). How high-commitment HRM relates to PC violation and outcomes: the mediating role of supervisor support and PC fulfilment at individual and organizational levels. Eur. Manag. J. 38, 462-476. doi: 10.1016/j.emj.2019.12.003

Lee, C. K., Song, H. J., Lee, H. M., Lee, S., and Bernhard, B. J. (2013). The impact of CSR on casino employees' organizational trust, job satisfaction, and customer orientation: an empirical examination of responsible gambling strategies. Int. J. Hosp. Manag. 78, 20-37. doi: 10.1016/j.ijhm.2012.10.011

Lindgreen, A., Swaen, V., and Johnston, W. J. (2009). Corporate social responsibility: an empirical investigation of U.S. organizations. J. Bus. Ethics 85 , 303-323. doi: 10.1007/s10551-008-9738-8

Maignan, I., and Ferrell, O. C. (2004). Corporate social responsibility and marketing: an integrative framework. J. Acad. Mark. Sci. 32, 3-19. doi: 10.1177/ 0092070303258971

Maon, F., Lindgreen, A., and Swaen, V. (2009). Designing and implementing corporate social responsibility: an integrative framework grounded in theory and practice. J. Bus. Ethics 87, 71-89. doi: 10.1007/s10551-008-9804-2

Masters, M. F., Albright, R. R., and Eplion, D. (2006). What did partnerships do? Evidence from the federal sector. ILR Review 59, 367-385. doi: 10.1177/ 001979390605900302

McWilliams, A., and Siegel, D. (2001). Corporate social responsibility: a theory of the firm perspective. Acad. Manag. Rev. 26, 117-127. doi: 10.5465/AMR.2001. 4011987

Mory, L., Wirtz, B. W., and Göttel, V. (2016). Factors of internal corporate social responsibility and the effect on organizational commitment. Int. J. Hum. Resour. Manag. 27, 1393-1425. doi: 10.1080/09585192.2015.1072103

Mossholder, K., Richardson, H., and Settoon, R. (2011). Human resource systems and helping in organizations: a relational perspective. Acad. Manag. Rev. 36, 33-52. doi: 10.5465/amr.2009.0402

Muthén, L. K., and Muthén, B. O. (1998-2018). Mplus User's Guide, 8th Edn, Los Angeles, CA: Author.

Newman, A., Cooper, B., Holland, P., Miao, Q., and Teicher, J. (2019). How do industrial relations climate and union instrumentality enhance employee performance? the mediating effects of perceived job security and trust in management. Hum. Resour. Manage. 58, 35-44. doi: 10.1002/hrm.21921

Newman, A., Nielsen, I., and Miao, Q. (2015). The impact of employee perceptions of organizational corporate social responsibility practices on job performance and organizational citizenship behavior: evidence from the Chinese private sector. Int. J. Hum. Resour. Manag. 26, 1226-1242. doi: 10.1080/09585192.2014. 934892

Persson, S., and Wasieleski, D. (2015). The seasons of the psychological contract: overcoming the silent transformations of the employer-employee relationship. Hum. Resour. Manag. Rev. 25, 368-383. doi: 10.1016/j.hrmr.2015.02.003

Podsakoff, P. M., MacKenzie, S. B., and Podsakoff, N. P. (2012). Sources of method bias in social science research and recommendations on how to control it. Annu. Rev. Psychol. 63, 539-569. doi: 10.1146/annurev-psych-120710-100452

Preacher, K. J., Zyphur, M. J., and Zhang, Z. (2010). A general multilevel SEM framework for assessing multilevel mediation. Psychol. Methods 15, 209-233. doi: $10.1037 / \mathrm{a} 0020141$

Pyman, A., Holland, P., Teicher, J., and Cooper, B. K. (2010). Industrial relations climate, employee voice and managerial attitudes to unions: an Australian study. Br. J. Ind. Relations 48, 460-480. doi: 10.1111/j.1467-8543.2009.00772.x

Raja, U., Johns, G., and Bilgrami, S. (2011). Negative consequences of felt violations: the deeper the relationship, the stronger the reaction. Appl. Psychol. 60, 397-420. doi: 10.1111/j.1464-0597.2011.00441.x

Richard, O. C., McMillan-Capehart, A., Bhuian, S. N., and Taylor, E. C. (2009). Antecedents and consequences of psychological contracts: does organizational culture really matter? J. Bus. Res. 62, 818-825. doi: 10.1016/j.jbusres.2008. 04.001
Robinson, S. L., and Rousseau, D. M. (1994). Violating the psychological contract: not the exception but the norm. J. Organ. Behav. 15, 245-259. doi: 10.1002/job. 4030150306

Rousseau, D. M. (2001). Schema, promise and mutuality: the building blocks of the psychological contract. J. Occup. Organ. Psychol. 74, 511-541. doi: 10.1348/ 096317901167505

Rupp, D. E., Shao, R., Thornton, M. A., and Skarlicki, D. P. (2013). Applicants' and employees' reactions to corporate social responsibility: the moderating effects of First-Party justice perceptions and moral identity. Pers. Psychol. 66, 895-933. doi: 10.1111 /peps. 12030

Salancik, G. R., and Pfeffer, J. (1978). A social information processing approach to job attitudes and task design. Adm. Sci. Q. 239, 224-253. doi: 10.2307/2392563

Schneider, B., Ehrhart, M. G., and MacEy, W. H. (2013). Organizational climate and culture. Annu. Rev. Psychol. 64, 361-388. doi: 10.1146/annurev-psych-113011143809

Serra-Cantallops, A., Peña-Miranda, D. D., Ramón-Cardona, J., and MartorellCunill, O. (2018). Progress in research on CSR and the hotel industry (20062015). Cornell Hosp. Q. 59, 15-38. doi: 10.1177/1938965517719267

Shen, J., and Zhang, H. (2019). Socially responsible human resource management and employee support for external CSR: roles of organizational CSR climate and perceived CSR directed toward employees. J. Bus. Ethics. 156, 875-888. doi: 10.1007/s10551-017-3544-0

Shih, C. T., and Chen, S. J. (2011). The social dilemma perspective on psychological contract fulfilment and organizational citizenship behaviour. Manag. Organ. Rev. 7, 125-151. doi: 10.1111/j.1740-8784.2010.00202.x

Snape, E. D., and Redman, T. (2012). Industrial relations climate and union commitment: an evaluation of workplace-level effects. Ind. Relat. 51, 11-28. doi: 10.1111/j.1468-232X.2011.00662.x

Story, J. S. P., and Castanheira, F. (2019). Corporate social responsibility and employee performance: mediation role of job satisfaction and affective commitment. Corp. Soc. Responsib. Environ. Manag. 26, 1361-1370. doi: 10. $1002 /$ csr.1752

Tajfel, H., and Turner, J. C. (1986). "The social identity theory of intergroup behaviour," in Psychology of Intergroup Relations, eds S. Worchel and W. G. Austin (Chicago: Nelson Hall), 7-24.

Turker, D. (2009). Measuring corporate social responsibility: a scale development study. J. Bus. Ethics 85, 411-427. doi: 10.1007/s10551-008-9780-6

Valizade, D., Ogbonnaya, C., Tregaskis, O., and Forde, C. (2016). A mutual gains perspective on workplace partnership: employee outcomes and the mediating role of the employment relations climate. Hum. Resour. Manag. J. 26, 351-368. doi: $10.1111 / 1748-8583.12113$

Van Scotter, J. R., and Motowidlo, S. J. (1996). Interpersonal facilitation and job dedication as separate facets of contextual performance. J. Appl. Psychol. 81, 525-531. doi: 10.1037/0021-9010.81.5.525

Wang, W., Fu, Y., Qiu, H., Moore, J. H., and Wang, Z. (2017). Corporate social responsibility and employee outcomes: a moderated mediation model of organizational identification and moral identity. Front. Psychol. 8:3389. doi: 10.3389/fpsyg.2017.01906

Wang, X.-H. F., Yang, J., Cao, R., and Lee, B. Y. (2019). Corporate social responsibility and collective OCB: a social identification perspective. Front. Psychol. 10:2720. doi: 10.3389/fpsyg.2019.02720

Xi, M., Xu, Q., Wang, X., and Zhao, S. (2017). Partnership practices, labor relations climate, and employee attitudes: evidence from China. ILR Rev. 70, 1196-1218. doi: 10.1177/0019793916684778

Xiao, M., Cooke, F. L., Xu, J., and Bian, H. (2019). To what extent is corporate social responsibility part of human resource management in the Chinese context? A review of literature and future research directions. Hum. Resour. Manag. Rev. 30:100726. doi: 10.1016/j.hrmr.2019.100726

Conflict of Interest: The authors declare that the research was conducted in the absence of any commercial or financial relationships that could be construed as a potential conflict of interest.

Copyright (c) 2021 Fang, Fan, Nepal and Chang. This is an open-access article distributed under the terms of the Creative Commons Attribution License (CC BY). The use, distribution or reproduction in other forums is permitted, provided the original author(s) and the copyright owner(s) are credited and that the original publication in this journal is cited, in accordance with accepted academic practice. No use, distribution or reproduction is permitted which does not comply with these terms. 